\title{
Fiki Naki's Subtitling Strategies in YouTube Channel
}

\author{
Noveyona Eny ${ }^{1,{ }^{*}}$ Minda Murni Sri $^{2}$ Dirgeyasa I Wy ${ }^{3}$ \\ ${ }^{I}$ English Applied Linguistic Study Program, Post-Graduate, State University of Medan \\ ${ }^{2}$ State University of Medan \\ ${ }^{3}$ State University of Medan \\ *Corresponding author. Email: enoveyona@gmail.com
}

\begin{abstract}
This study was about subtitling strategies used in Fiki Naki YouTube Channel. The objective of the study was to categorize the types of subtitling strategies used in Fiki Naki YouTube Channel. The study was descriptive qualitative. The subject of the study was the video of Fiki Naki taken on May 2021 complete with its subtitle. The data of the study was the sentences and the subtitle downloaded from YouTube. The data categorized based on Gottlieb (1992). The results showed that there were 9 subtitling strategies found in the video of Fiki with total data 490. 68 (13.91\%) for transfer strategy, $38(7.77 \%)$ for imitation strategy, $4(0.82 \%)$ for transcription strategy, $47(9.61 \%)$ for expansion strategy, $171(35.58 \%)$ paraphrase strategy, $81(16.57 \%)$ for condensation strategy, $35(7.16 \%)$ deletion strategy and 41 $(8.38 \%)$ for resignation strategy. therefore, the most dominant subtitling strategy applied in Fiki's YouTube channel found was paraphrase strategy and dislocation strategy was not found in the video.
\end{abstract}

Keywords: subtitle, subtitle strategies, Fiki Naki, YouTube Channel.

\section{INTRODUCTION}

In this $21^{\text {st }}$ century, communication and technology cannot be separated. People from the younger generation to the older ones have been exposed to the internet. With this sophisticated technology, people from anywhere can communicate with anyone from any place across the world in just one click away. We are now in the digital era of communication, which gives people an option to use their devices, such as mobile phone, laptop, and tablet, which are connected to the internet as the tools of communication instead of face-to-face. The internet is such a game changer. It is not only changing the way people communicate but also in their lifestyle of watching. Nowadays, people, especially the younger generation, like to watch YouTube instead of television. YouTube is one of the video-sharing platforms, which allow the users to create their own account and share their videos online. Fiki is a YouTube from Pekanbaru, Province of Riau, Indonesia. He has been capturing public attention, especially the young generation with his videos on YouTube. He shows his ability in speaking various kinds of languages as the content of his YouTube channel. English, Romanian, to Russian are the language examples he is speaking. This is known from the video on his personal YouTube channel. As an impact, his channel has been gaining about 4 million subscribers, which also watch and like his videos.
Ome TV is a video-chat website which allows the users to do video chatting to other people of different gender, culture, backgrounds, language and countries all over the world randomly. It means that the condition is not allowed the users to choose to whom they are going to talk to or from what country the other acquaintance will be. Young people nowadays prefer talking to strangers on the internet including Fiki who is also using this website to communicate with strangers from other countries. He uses this as the media. What is interesting is, on Fiki's YouTube channel, the conversational videos are completed with subtitle, which is provided in Bahasa Indonesia. The subtitle is commonly found in the movie. This is why the writer would like to conduct this field as the source research and expects to gain a new insight to the translation field especially the subtitling strategies in the conversational chatting video instead in the movie. The following are some preliminaries data found by the researcher by the data source in one of Fiki's video subtitling:

Fiki’s utterance $\quad: \quad$ Too many questions

Subtitle

: Banyak bet pertanyaanya.

Based on the example above, it can be seen that there is the word bet subtitled in the video, which is supposed to be banget. The word itself is formed in an unusual term of Bahasa Indonesia. It is supposed to be translated from 
the word 'too'. However, Fiki provides the subtitle in a different way, which counts as a transcription strategy proposed by Gottlieb. [1]

In doing this research, there was previous research concerned on subtitling strategies. Kholiq (2020) with the same theory by Gottlieb analyzed the subtitle of The Boss Baby: Back in Business movie series. This research aimed to investigate subtitling strategies. The result showed that that there are only 6 strategies in the web television appear, namely: transfer strategy, decimation strategy, deletion strategy, paraphrase strategy, imitation strategy, and transcription strategy. [4]

Considering the phenomena, the researcher is curious to do research at investigating the English sentences and the subtitle contain with that applies in Fiki Naki's YouTube Channel.

\section{REVIEW OF LITERATURE}

\subsection{Subtitle}

Subtitling is kind of translation which present the result of the translation in the written text especially in the lower part of the screen which is including the original dialog of the actor complete with the sequence of the image. [2]

\subsection{Subtitle Strategies}

Agustina and Joni (2019) states that strategies refer to 'a general way of translating in its basic problem-solving sense as a plan that is implemented in a given context and is cognitive procedure not linguistic. [3] Gottlieb (1992) classifies impoliteness to ten strategies, they are:

1. Transfer Strategy is one kind of subtitle strategy which defined as the strategy of translating the source language correctly and completely. Transfer is the strategy of translating source language completely and accurately suitable with the context without changed message of the target language.

2. Imitation Strategy is used when there is the proper noun or the same forms, such as; people's names, places, a title of a book, country, brand products.

3. Transcription Strategy is used in some cases where an unusual term exists even in the source; language, for example; there is a third language or nonsense language used.

4. Expansion Strategy is used when target language needs an explanation to make the message clearly and understood by viewers, because there is a different culture of source language with target language.

5. Paraphrase Strategy is the way of translator translating source language into target language composing with their own language in the same syntactic way without changing the message. Paraphrase strategy usually uses to make the target language easier to understand by viewers.

6. Dislocation Strategy is adopted when the dialog of source language employs some sort of special effects, such as a cartoon film which contains a silly song in it, where the translation of the effect is mimportant than the content.

7. Condensation Strategy is shortening the source language into target language, deletion of some parts of the utterance of the speaker that felt unimportant. The use of this strategy can lose part of the full meaning of source text.

8. Deletion Strategy uses when the translator deletes one or some words that perceive no need to translate into target language.

9. Decimation Strategy applied when there is an extreme form, it omits an important element which makes the audience confused and some taboo words such as when there is quarreling scene; the characters are talking too fast.

10. Resignation Strategy is used when there is no translation solution found by the translator and the meaning is inevitably lost.

\section{RESEARCH METHOD}

The objectives of this study are to investigate the types of subtitling strategies in Fiki's YouTube channel. Therefore, this study conducted based on qualitative research design. The data of this study were the English utterances complete with the subtitle in Fiki's video.The data analyzed based on the types of subtitling strategies by applying Miles, Huberman, and Saldana (2014) analysis model that consisted of three steps, namely: 1) data condensation, 2) data display, and 3) conclusion drawing and verification. [4]

\section{RESULTS}

From the research that has been done in analyzing English utterances with the subtitle, there were nine out of ten types of subtitling strategies found in Fiki Naki's Youtube channel proposed by Gottlieb (1992) with the total frequencies 490. Those types could see in the following table.

Table 1. The types of Subtitling Strategies

\begin{tabular}{llll}
\hline No & $\begin{array}{l}\text { Types of Subtitling } \\
\text { Strategies }\end{array}$ & Total & $\begin{array}{l}\text { Percentage } \\
(\%)\end{array}$ \\
\hline 1 & Transfer Strategy & 68 & 13.91 \\
\hline 2 & Imitation Strategy & 38 & 7.77 \\
\hline 3 & Transcription Strategy & 4 & 0.82 \\
\hline 4 & Expansion Strategy & 47 & 9.61 \\
\hline 5 & Paraphrase Strategy & 174 & 35.58 \\
\hline 6. & Dislocation Strategy & - & - \\
\hline 7. & Condensation Strategy & 81 & 16.57 \\
\hline 8. & Deletion Strategy & 35 & 7.16 \\
\hline 9. & Decimation Strategy & 1 & 0.20 \\
\hline 10. & Resignation Strategy & 41 & 8.38 \\
\hline & Total & 490 & 100 \\
\hline
\end{tabular}


It can be concluded that the most dominant type of subtitling strategy applied in Fiki's YouTube Channel found was Paraphrase Strategy while Dislocation Strategy was not found. The reason why Paraphrase strategy is the most applied one is because the video was informal which had a purpose to gain the attention of the viewers so they will feel entertained by reading the subtitle and keep watching the video. Besides, the reason why Dislocation strategy was not found is because there was no specific sound in the conversational video to be shown in the subtitle and Deletion strategy was applied instead of Dislocation strategy.

\section{DISCUSSION}

This study focused on the English utterances with the subtitle in Fiki Naki's YouTube channel. After analyzing the data, there were nine types of subtitling strategies, namely 1) Transfer Strategy, 2) Imitation Strategy, 3) Transcription Strategy, 4) Expansion Strategy, 5) Paraphrase Strategy, 6) Condensation Strategy, 7) Deletion Strategy, 8) Decimation Strategy and 9) Resignation Strategy while Dislocation strategy was not found in the data. The most dominant strategy used was Paraphrase Strategy because Fiki, as the video creator displays many informal Indonesia words or particle in the subtitle, which is contrarily different with the usual formal movie subtitle. The finding is not similar to the finding of the previous research conducted by Kholiq (2020) related to the types of subtitle strategies in the Boss Baby movie which only applied 6 types of strategies. [4] In this case, the difference between this finding with the current research potentially is due to the different type of data sources. It also means that different data lead to the different fulfillments of results of subtitling strategies.

\section{AUTHORS' CONTRIBUTIONS}

The findings of the research are expected to add up new horizons in translation study. In addition, hopefully, the findings will explore the new ideas for other researchers in investigating the language used in social context along with its functions in society itself, and also be able to give much contributions and insights to apply linguistics particularly in English which can be used as a reference for the similar study with different focus or object in the future. Briefly, the findings can add up more horizons to linguistics and also as a guide line for other researchers to conduct the further research related to translation study

\section{ACKNOWLEDGMENTS}

Researchers would like to express deep gratitude to anyone involved in helping in the form of support and guidance related to the completion of this research, especially to Prof, Dr, Sri Minda Murni, M.S., and also Prof, IWy Dirgeyasa, M.Hum., who have helped the author finishing this research, and thanks to Annual International Seminar on Transformative Education and Educational Leadership (AISTEEL) 2021, and the reviewers who have provided the opportunity for the author to share this research in terms of helping author, so that this research can be completed properly.

\section{REFERENCES}

[1] Gottlieb, H. (1992). Subtitling. A New University Discipline. In Dollerup \& Loddegaard (eds). Teaching Translation and Interpreting: Training,

[2] Diaz Cintaz J. and Remael A. 2007. Audiovisual Translation: Subtitling. Manchaster: St. Jerome.

[3] Agustina, Noni. \& Joni. (2019). The Subtitling Strategies Used in Indonesia Film. ELTIN Journal, Volume 7/II.

[4] Kholiq, Muhammad. \& Emrinne, Agustinne. (2020). Subtitling Strategies in "The Boss Baby: Back in Business" Series. Ethical Lingua Vol. 7, No. 1, 2020

[3] Bogdan, R C and S K, Biklen. (2007). Qualitative Research for Education: An Introduction to Theory and Methods 5th Edition. Boston: Allyn and Bacon

[4] Miles, M B., A, M Huberman and J, Saldana. (2014). Qualitative Data Analysis: A Methods Sourcebook 3rd Edition. Los Angeles: Sage Publications 